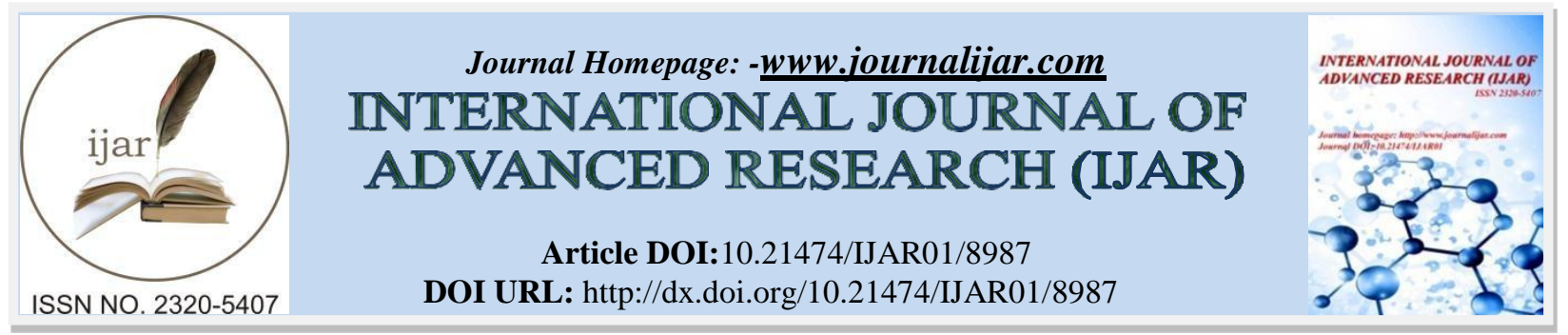

RESEARCH ARTICLE

\title{
ARTIFICIAL INTELLIGENCE IN INDIAN BANKING SECTOR: CHALLENGES AND OPPORTUNITIES.
}

\author{
Dr.C.Vijai. \\ Assistant Professor,Department of Commerce,St.Peter`s Institute of Higher Education and Research, Chennai,Tamil \\ Nadu,India.
}

\section{Manuscript Info}

\section{Manuscript History}

Received: 27 February 2019

Final Accepted: 29 March 2019

Published: April 2019

\section{Key words:-}

Artificial Intelligence, Fintech, block chain, banking technology, Intelligence.

\begin{abstract}
Artificial Intelligence (AI) is fast developing technology for across the world. The banking sector is becoming one of the first adopters of Artificial Intelligence. Banks are exploring and implementing technology in various ways. Artificial Intelligence is getting better and smarter day by day. In this paper, we will discuss how Artificial Intelligence is used in the Indian banking sector, what are the benefits and what are the Challenges facing India's Artificial Intelligence. Development that Artificial Intelligence offers to FinTech and the different ways in which it can improve the operations of an Indian banking sector.
\end{abstract}

Copy Right, IJAR, 2019,. All rights reserved.

Introduction:-

Artificial Intelligence (AI) is fast evolving as the go-to technology for companies across the world to personalize experience for individuals. The technology itself is getting better and smarter day by day, allowing more and newer industries to adopt the AI for various applications. Banking sector is becoming one of the first adopters of AI. And just like other segments, banks are exploring and implementing the technology in various ways.

The rudimentary applications AI include bring smarter chat-bots for customer service, personalizing services for individuals, and even placing an AI robot for self-service at banks. Beyond these basic applications, banks can implement the technology for bringing in more efficiency to their back-office and even reduce fraud and security risks.

Unsurprisingly, research firms are bullish on the potential of AI in banking. According to Fintech India report by PwC in 2017, the global spending in AI applications touched \$5.1 billion, up from \$4 billion in 2015. There is a keen interest in the Indian banking sector as well. ${ }^{1}$

\section{Objectives}

1. To study the areas where the artificial intelligence is being used by the banks

2. To study about the application of Artificial intelligence in Banking Sector

1 "Artificial Intelligence in Indian banking: Challenges and opportunities c..." 6 Jul. 2018, https://www.livemint.com/AI/v0Nd6Xkv0nINDG4wQ2JOvK/Artificial-Intelligence-in-Indian-banking-Challengesand-op.html. Accessed 19 Dec. 2018.

Corresponding Author:-Dr.C.Vijai. Address:-Assistant Professor,Department of Commerce,St.Peter's Institute of Higher Education and Research, Chennai,Tamil Nadu,India. 


\section{Scope}

The study covers the technological developments in Indian banking sector only.

\section{Methodology:-}

The study is descriptive in nature and is based on secondary data. The data are collected from various reports, journals, news articles, various bank portals, RBI portal and internet sources.

\section{What is artificial intelligence?}

According to the father of Artificial Intelligence, John McCarthy, it is -The science and engineering of making intelligent machines, especially intelligent computer programs.

Artificial Intelligence is a way of making a computer, a computer-controlled robot, or a software think intelligently, in the similar manner the intelligent humans think.

AI is accomplished by studying how human brain thinks and how humans learn, decide, and work while trying to solve a problem, and then using the outcomes of this study as a basis of developing intelligent software and systems. ${ }^{2}$

\section{Artificial Intelligence Overview}

AI refers to _Artificial Intelligence _which means making machines capable of performing intelligent tasks like human beings. AI performs automated tasks using intelligence. The term Artificial Intelligence has two key components:

1. Automation

2. Intelligence

\section{Stages of Artificial Intelligence}

\section{Stage 1 - Machine Learning}

It is a set of algorithms used by intelligent systems to learn from experience.

\section{Stage 2 - Machine Intelligence}

These are the advanced set of algorithms used by machines to learn from experience. Eg - Deep Neural Networks. Artificial Intelligence technology is currently at this stage

\section{Stage 3 - Machine Consciousness}

It is self-learning from experience without the need of external data.

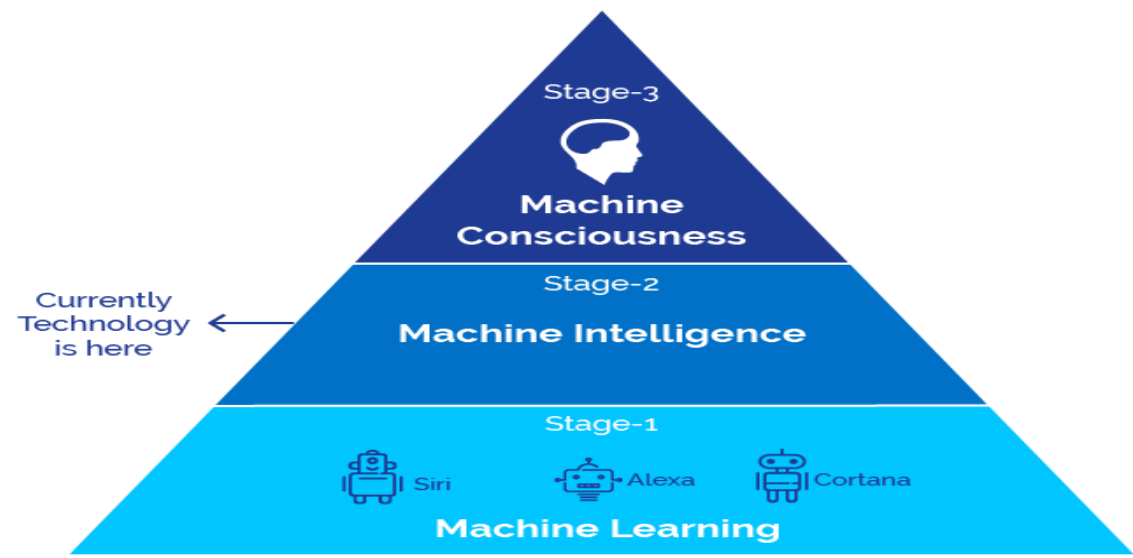

Stages of Artificial Intelligence

Source: https://www.upwork.com

2 https://www.tutorialspoint.com/artificial_intelligence/artificial_intelligence_overview.htm 


\section{Types Of Artificial Intelligence}

ANI - Artificial Narrow Intelligence

It comprises of basic/role tasks such as those performed by chatbots, personal assistants like SIRI by Apple and Alexa by Amazon.

\section{AGI - Artificial General Intelligence}

Artificial General Intelligence comprises of human-level tasks such as performed by self-driving cars by Uber, Autopilot by Tesla. It involves continual learning by the machines.

\section{ASI - Artificial Super Intelligence}

Artificial Super Intelligence refers to intelligence way smarter than humans.

\section{Difference between Nlp, AI, MI, DI \& Nn}

\section{AI or Artificial Intelligence}

Building systems that can do intelligent things.

\section{NLP or Natural Language Processing}

Building systems that can understand language. It is a subset of Artificial Intelligence.

\section{ML or Machine Learning}

Building systems that can learn from experience. It is also a subset of Artificial Intelligence.

NN or Neural Network

Biologically inspired network of Artificial Neurons.

\section{DL or Deep Learning}

Building systems that use Deep Neural Network on a large set of data. It is a subset of Machine Learning. ${ }^{3}$

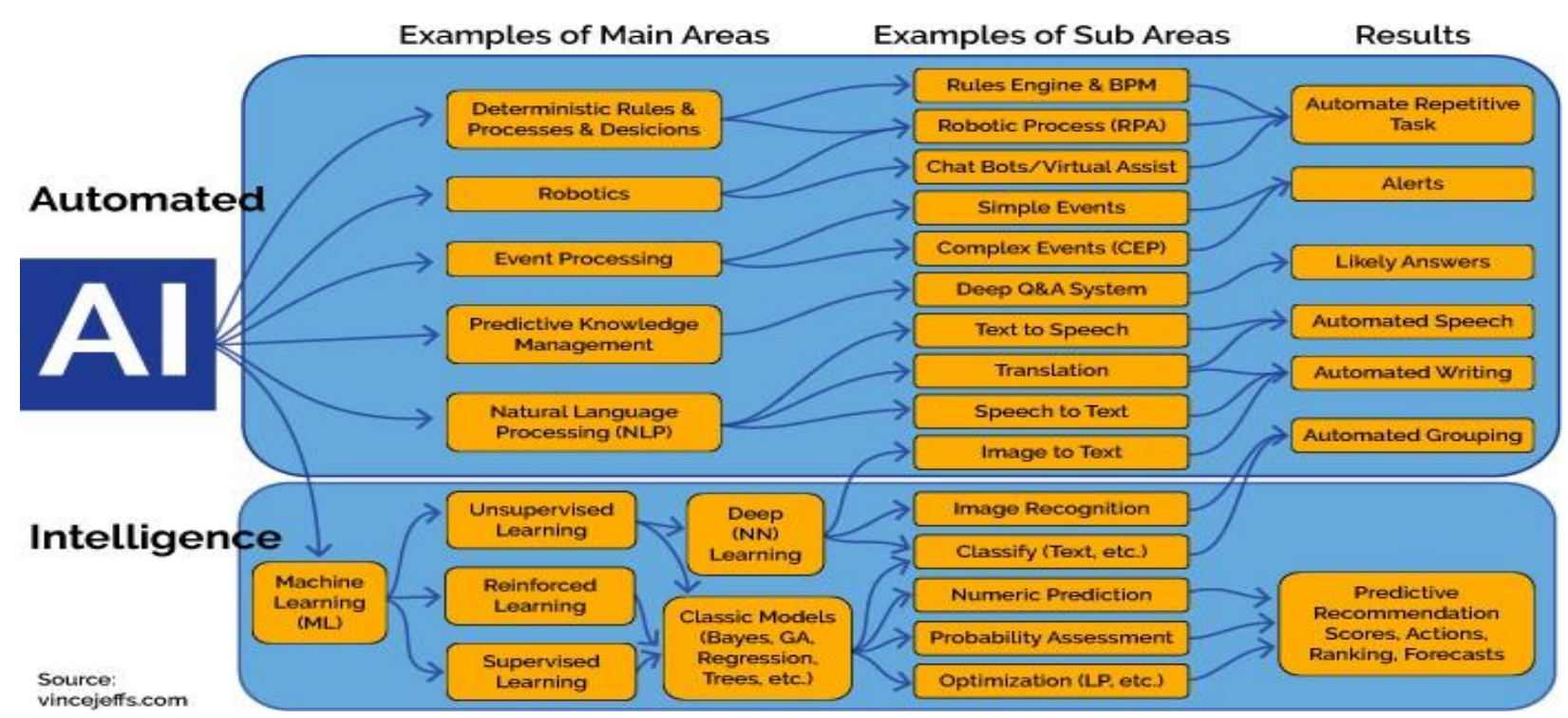

\section{Artificial Intelligence History}

The term artificial intelligence was coined in 1956, but AI has become more popular today thanks to increased data volumes, advanced algorithms, and improvements in computing power and storage.

Early AI research in the 1950s explored topics like problem solving and symbolic methods. In the 1960s, the US Department of Defense took interest in this type of work and began training computers to mimic basic human

3Overview of Artificial Intelligence and Natural Language Processing https://www.upwork.com/hiring/for- clients/artificialintelligence-and-natural-language-processing-in-big-data/. 
reasoning. For example, the Defense Advanced Research Projects Agency (DARPA) completed street mapping projects in the 1970s. And DARPA produced intelligent personal assistants in 2003, long before Siri, Alexa or Cortana were household names.

This early work paved the way for the automation and formal reasoning that we see in computers today, including decision support systems and smart search systems that can be designed to complement and augment human abilities.

While Hollywood movies and science fiction novels depict AI as human-like robots that take over the world, the current evolution of AI technologies isn't that scary - or quite that smart. Instead, AI has evolved to provide many specific benefits in every industry. Keep reading for modern examples of artificial intelligence in healthcare, retail and more. $^{4}$

\section{Artificial Intelligence Industry In India - The Current Status}

A news report published in October in The Economic Times said, - Start-ups witness 108\% growth in funding in India in 2018.\| The news report further mentioned that Artificial Intelligence was among those domains which witnessed fastest adoption among industry sectors. Currently there are about 400 start-ups working on AI and machine learning domains. About $\$ 150$ million dollars is invested in India's AI sector by private players alone and the number has been growing since 2016. Though there has been growth, India lags far behind countries like US and China in terms of investment. With a copious pool of STEM talent and with growing population of youngsters, India will be banking on AI for its economic growth and improvement in quality of life of its citizens.

There are several start-ups that are based in cities such as Bengaluru, New Delhi, Mumbai and Hyderabad which work on artificial intelligence principles to serve consumers better. Their product range vary from multi-lingual chat bots to online shopping assistance and automated consumer data analysis. The companies have been working in areas such as e-commerce, healthcare, edtech, fintech etc. Though in their nascent stage, the performance of these companies have been promising. ${ }^{5}$

\section{Indian Banks And The Technology}

The balanced approach followed by Indian central bank, Reserve Bank of India, is another major factor in any new technology adoption in Indian banking sector. In the last few years - especially during the governorship of Raghuram Rajan and his successor Urjit Patel-RBI has taken a cautious but pragmatic view of embracing new technologies, often forcing technology adoption on banks through regulation, wherever it has seen scope to enhance customer experience and efficiency using a particular technology. RBI's proactive push of new technology adoption has not just been restricted to creating policy frameworks. It has used a mix of regulation, evangelism and even worked with the industry to make things easier and effective.

The creation of National Payment Corporation of India (NPCI) which has significantly brought down the cost of electronic transactions is a case in point. The regulator also has an academic/research unit, Institute of Development and Research in Banking Technology (IDRBT) which keeps studying the opportunities and challenges in new technology areas. It is not a coincidence that both these units have been actively involved in testing out blockchain as a proof of concept.

India's position is quite unique here. It is a fact that India is a tech-hub. Apart from being a large technology outsourcing destination, India is also the home to vendors with a large core banking market share globally. Two of the top three core banking solution vendors - Infosys and TCS - are headquartered in India. Of late, India has also seen a lot of activity in the fintech arena. The country has become one of the global fintech hubs. While in many developed markets, fintechs and banks have enjoyed an uneasy relationship, in India, most progressive banks like

4 "Artificial Intelligence - What it is and why it matters | SAS." https://www.sas.com/en_us/insights/analytics/whatis-artificial-intelligence.html. Accessed 19 Dec. 2018.

5 The future of artificial intelligence industry in india,November 15, $2018 \mathrm{https} / / /$ inurture.co.in/blog/the-future-ofartificial-intelligence-industry-in-india/ 
ICICI Bank, Axis Bank and HDFC Bank have proactively gone to fintechs, creating contests and hackathons to get the best of innovations, sometimes even sharing their APIs with these fintechs.

BankChain was announced on 8 February 2017 by SBI, India's largest bank. It's a 30+ member consortium led by SBI, the country's largest lender, and includes banks, NBFCs and the National Payments Corporation of India (NPCI), an organization set up by Indian banks to support retail payments. Simply put, BankChain is a community of banks for exploring, building and implementing blockchain solutions. BankChain is supported by Pune-based startup Primechain Technologies to create these solutions. Currently, it has 37 members and 8 live projects. ${ }^{6}$

\section{Artificial Intelligence Technology In Banking And Finance Personalized Financial Services}

Personalized connect will reach new heights as automated financial advisors and planners provide expertise in making financial decisions. They analyze market temperament against the user's financial goals and personal portfolio, and offer recommendation regarding stocks and bonds.

\section{Smart Wallets}

Digital wallets are touted as the future of real-world payment technologies, with major players like Google, Apple, Paypal and others, jumping on the bandwagon and developing their own payment gateways. This decreases the dependence on physical cash, thereby expanding the reach of money to greater levels.

\section{Underwriting}

The insurance sector is also coming up with a storm as they are moving towards congruent automation. By utilizing AI systems that automate the underwriting process, the organizations come armed with more granular information to empower their decisions.

\section{Voice Assisted Banking}

Physical presence is slowly fading away as technology empowers customers to use banking services with voice commands and touch screens. The natural language technology can process queries to answer questions, find information, and connect users with various banking services. This reduces human error, systemizing the efficiency.

\section{Data-driven AI applications for lending decisions}

Applications embedded in end-user devices, personal robots, and financial institution servers are capable of analyzing a huge volume of data, providing customized financial advice, calculations and forecasts. These applications can also develop financial plans and strategies through research, regarding various customized investment opportunities, loans, rates, fees, etc and track the progress.

\section{Customer support}

As speech processing and natural language processing technologies mature, we are drawing closer to the day, when computers could handle most customer service queries. This would mark an end to waiting in line and hence result in happier customers.

\section{Digitalization instead of branch lines}

Banking is a lengthy process, with past records of long queues and sluggish response marring the productivity. Even opening a bank account was viewed in negative terms as harried consumers would run pillar to post, while getting the necessary documentation complete. Digitization of documentation eases that pain and creates a comprehensive platform, where the consumers and providers connect.

\section{Blockchain hastening payments}

The customer base that banks serve is going through a major shift in terms of buying behaviors and preferences, driven by the digital revolution, particularly social media and mobile. An increased demand for more choice and control in how they interact with a bank is on a rise. Sluggish payment processes will be a thing of the past as

6 "Impact of Information Technology in Indian Banking Industry - Banking ...." 17 May. 2018, http://www.bankingfinance.in/impact-of-information-technology-in-indian-banking-industry.html. Accessed 22 Dec. 2018 . 
Blockchain is set to inculcate the advantage of real-time payment process, hastening up the procedure of payment, thereby increasing support and satisfaction. ${ }^{?}$

\section{Artificial Intelligence Banking In India}

According to PwC FinTech Trends Report (India) 2017, global investment in AI applications touched USD 5.1 billion (Euro 4.3 billion) in 2016. Not only PNB but banks like SBI, HDFC, ICICI, HSBC and Axis banks in India have turned towards AI.

\section{State Bank of India (SBI)}

SBI launched a national hackathon called _Code For Bank' for developers, startups and students to come up with innovative ideas and solutions for banking sector that focuses on technologies such as predictive analytics, fintech/blockchain, digital payments, IoT, AI, machine learning, BOTS and robotic process automation. The bank is currently using an AI- based solution developed by Chapdex (the winning team from its first hackathon), that captures the facial expressions of the customers and helps them in understanding the behavior of its customers.

\section{HDFC Bank}

HDFC bank has developed an AI- based chatbot called_Eva' (Electronic Virtual Assistance), built by Bengalurubased Senseforth that has addressed over 2.7 million customer queries, interacted with over 530,000 unique users, and held 1.2 million conversations. The device can provide answers in less than 0.4 seconds and has in the first few days of its launch answered more than 100,000 queries from thousands of customers from 17 countries. The bank is also experimenting with in-store robotic applications called IRA (Intelligent Robotic Assistant).

\section{ICICI Bank}

ICICI bank has deployed software robotics in over 200 business processes across various functions of the company. Calling it the robotic software the bank claims it to be the first in the country and among very few in the world to deploy this technology, that emulates human actions to automate and perform repetitive, high volume and time consuming business tasks.

\section{Axis Bank}

Axis Bank recently launched an AI and NLP (Natural Language Processing) enabled app for conversational banking, to help consumers with financial and non-financial transactions, answer FAQs and get in touch with the bank for loans. ${ }^{8}$

\section{The Challenges Facing India's Ai Development}

1. AI-based applications to date have been driven largely by the private sector and have been focused primarily in consumer goods. The emergent scale and implications of the technology make it imperative for policymakers in government to take notice.

2. Early lessons of AI success in the United States, China, South Korea, and elsewhere offer public and private funding models for AI research that India should consider.

3. The sequential system of education and work is outdated in today's economic environment as the nature of jobs shifts rapidly and skills become valuable and obsolete in a matter of years. ${ }^{9}$

\section{Benefits of ai for banking sector fraud detection:}

Anomaly detection can be used to increase the accuracy of credit card fraud detection and anti-money laundering.

\section{Customer Support and Helpdesk:}

Humanoid Chatbot interfaces can be used to increase efficiency and reduce cost for customer interactions.

7 Ram Punamaraju 2018,How Artificial Intelligence Is Changing The Banking Sector,http://www.cxotoday.com/story/impact-of-artificial-intelligence-on-the-banking-sector/

8 "Artificial Intelligence comes to the rescue of banks Banks trusting machines more than humans 2018,https://mediaindia.eu/business-politics/artificial-intelligence-comes-to-the-rescue-of-banks/

9 "India and the Artificial Intelligence Revolution - Carnegie India ..." 11 Aug. 2016, https://carnegieindia.org/2016/08/11/india-and-artificial-intelligence-revolution-pub-64299. Accessed 29 Dec. 2018. 


\section{Risk Management:}

Tailored products can be offered to clients by looking at historical data, doing risk analysis, and eliminating human errors from hand-crafted models.

\section{Security:}

Suspicious behaviour, logs analysis, and spurious emails can be tracked down to prevent and possibly predict security breaches.

\section{Digitization and automation in back-office processing:}

Capturing documents data using OCR and then using machine learning/AI to generate insights from the text data can greatly cut down back-office processing times.

\section{Wealth management for masses:}

Personalized portfolios can be managed by Bot Advisors for clients by taking into account lifestyle, appetite for risk, expected returns on investment, etc.

\section{ATMs:}

Image/face recognition using real-time camera images and advanced AI techniques such as deep learning can be used at ATMs to detect and prevent frauds/crimes.

\section{Conclusion:-}

Artificial intelligence has many benefits to offer for the banking sector. Artificial intelligence is changing business processes and customer-facing services in the banking sector in India. It is also being used to meet regulatory compliance, detect fraud, and assess individual creditworthiness. The application of AI has the potential to create more efficient business processes, offer personalized services, and assist in larger goals such as financial inclusion. There is no doubt that the recent push towards digitalization is rapidly influencing the traditional banking models. However, it has also exposed the institutions to increasing cyber security threats and vulnerabilities. The banks are increasingly looking at emerging technologies such as block chain and analytics in creating an active defense mechanism against cybercrimes.

\section{References:-}

1. M. Bhuvana, P. G. Thirumagal and S .Vasantha, Big Data Analytics - A Leveraging Technology for Indian Commercial Banks, Indian Journal of Science and Technology, Vol 9 (32), August 2016.

2. -Banking in the age of disruption,\| EY, February 2017.

3. http://www.latinia.com/IF/Documentos/Intelligence_Digital_Banking.pdf

4. Shivkumar Goel and Nihaal Mehta A Survey on the Role of Artificial Intelligence in FinTech, International Journal of Innovative Research in Computer and Communication Engineering, Vol. 5, Issue 6, June 2017.

5. Driving AI for Financial Services - Simularity Whitepaper

6. https://www.livemint.com/AI/v0Nd6Xkv0nINDG4wQ2JOvK/Artificial-Intelligence-in-Indian-bankingChallenges-and-op.html.

7. https://www.financialexpress.com/money/8-amazing-ways-consumers-can-benefit-from-artificial-intelligences- impacton-banking-financial-sectors/985652/

8. http://www.cxotoday.com/story/impact-of-artificial-intelligence-on-the-banking-sector/

9. https://www.financialexpress.com/industry/banking-finance/sbi-turns-to-artificial-intelligence-powered-chatassistant-here-is-what-you-get/870752/

10. https://dzone.com/articles/ai-and-the-future-of-banking

11.https://www.maparesearch.com/5-use-cases-ai-banking-beyond-helpful-chatbots/

12.https://www.tutorialspoint.com/artificial_intelligence/artificial_intelligence_overview.hm 